\title{
Cultural Conceptualization and Cross-Cultural Misunderstanding in Iranian English
}

\author{
Mehdi Solhi Andarab ${ }^{1, *}$, Asgar Mahmoudi ${ }^{2}$ \\ ${ }^{1}$ English Preparatory Program, Istanbul Medipol University, Istanbul, Turkey \\ ${ }^{2}$ Department of English Language, Ardabil Branch, Islamic Azad University, Ardabil, Iran \\ Email adress: \\ solhi.mehdi@gmail.com (M. S. Andarab), Mahmoudi301@gmail.com (A. Mahmoudi)
}

\section{To cite this article:}

Mehdi Solhi Andarab, Asgar Mahmoudi. Cultural Conceptualization and Cross-Cultural Misunderstanding in Iranian English. International Journal of Language and Linguistics. Vol. 3, No. 6, 2015, pp. 353-359. doi: 10.11648/j.ij11.20150306.16

\begin{abstract}
Cross-cultural Misunderstanding has always been a conundrum for individuals who involve in intercultural communication. Coming from different cultural backgrounds, individuals tend to behave in a way that is appropriate to their own cultural norms which might pose serious problems for them. These cultural norms are what Sharifian (2010) titles cultural conceptualizations. Cultural conceptualizations are conceptual structures such as schemas, categories, and metaphors that come into existence as a result of interactions between members of a cultural group. This study elaborates on a number of important Iranian cultural schemas, such as 'expressing thankfulness', 'making request' and 'complimenting', and explores how these cultural schemas can potentially culminate in cross-cultural misunderstanding when communicating in English. This study argues in favor of enhancing people's meta-cultural competence, which is a prerequisite for successful communication in contexts in which English operates as an international language.
\end{abstract}

Keywords: Cultural Conceptualizations, Cultural Schemas, Intercultural Competence

\section{Introduction}

There are two issues with respect to vocabulary knowledge that should be considered: the relationship between vocabulary and context and the connections between words. Many word knowledge aspects, according to Schmitt (2014), are related to the use of vocabulary in context, that is, knowing where, when, and how to use it. Within the global dimensions paradigm too Zareva (2010) refers to the relationship between vocabulary growth and improvement in lexicon connectivity structure that adds to the depth of vocabulary knowledge. It follows that natives and nonnatives' success in communicating pragmatic meanings to each other is to a great extent dependent on non-natives' depth of vocabulary knowledge.

Communication success would be at risk, especially when less proficient non-native speakers use language productively because, as Schmitt (2014) puts it, productive mode requires more word knowledge components, many of them contextual. This does not, however, mean that receptive mode will not be affected by a lack of vocabulary knowledge depth. Receptive problems manifest themselves specifically when 'international students' encounter metaphoric language
(Littlemore, 2001; Littlemore, Trautman Chen, Koester, \& Barnden, 2011). Littlemore (2001) refers to two types of receptive pragmatic failure: misunderstanding and nonunderstanding. Both of these problems can hinder nonnatives' understanding of metaphoric expressions presented to them. Misunderstanding is particularly important because, as Littlemore et.al. (2011) say, in misunderstanding students usually do not seek clarification. This claim is in line with Taguchi (2008) who, after a four-months-long study, found that exposure enhances comprehension speed of pragmatic meanings but not comprehension accuracy. Zheng's (2014) qualitative data analysis also revealed that learners' development of semantic verbal awareness is slow, incremental, and characterized by attrition.

It is not difficult to extrapolate from vocabulary depth knowledge to conventionalized expressions' depth knowledge to understand how challenging the utilization of these expressions might be for L2 learners. Kathleen Bardovi-Harlig was one of those researchers who extended vocabulary depth knowledge to the learning of conventionalized expressions by non-natives. In her 2014 study of learning these expressions, Bardovi-Harlig employed a modified version of Vocabulary Knowledge Scale (VKS) and found a significant role for proficiency of 
the learners, host-environment experience, and the expressions themselves. In Bardovi-Harlig's study the learners were for the most part familiar with the expressions (less than five percent of the expressions were reported as not being recognized) but the definitions they provided and the uses they put the expressions to did not match sometimes. There were also examples of failure in the use of expressions among the participants, especially when they were required to make fine-grained differentiations. For example, while 'Nice to meet you' and 'Nice to see you' both may be used at the beginning or end of an encounter, the former is used only when people meet each other for the first time. BardoviHarlig reports that non-natives were unable to make this differentiation whereas there was no overlap in natives' use of them.

An understanding of the relationship between language and context and, following from that, between what is said and what should be understood is crucial (Johnstone, 2008; Paltridge, 2012). Johnstone, for example, states that there are situations in which discourse is interpreted in pre-set ways or even the norms are so stringent that they are codified in books or explained overtly. Johnstone (2008) explains further that people are usually not aware or do not think in terms of these conventions and it is only when these convention are broken that it becomes clear what the expectations were.

What is at issue in relation to native and non-native contacts and in relation to L2 acquisition, however, is why the majority of L2 learners lack the pragmatic competence that is needed for cross-cultural communication. Of course, Zareva (2010) believes that the ultimate goal of learning a second language is not to pass for a native. The researcher also emphasizes that comparing existing L2 associative behavior to that maintained by native speakers is a controversial one. However, it is clear that many L2 learners spend a lot time and energy to approach native norms of communicative behavior.

In the review of the literature that Watson, Siska, and Wolfel (2013) provide for cross-cultural competence, they point out that there has recently been a shift from cultural awareness and knowledge to cross-cultural competence. The authors highlight the importance of placing students into environments where they can engage in communications in which pragmatic meanings are conveyed. They also believe that this cultural contact should be consolidated with regional awareness, i.e., "gaining of general knowledge about regional components that can lead to an ability to interpret the interrelationships among these components in a specific setting" (p. 65). The issue is a multifaceted one however. Wardhaugh \& Fuller, (2015) state that language in addition to being an individual possession is a social possession and "we would expect, therefore, that certain individuals would behave linguistically like other individuals" (p. 62), in other words, in the manner that is acceptable to its members. These norms of behavior get deeply rooted under the influence of culture and to get rid of them when placed in another context, which demands different norms, is by no means easy.

Lanas (2014), analyzing a group of studies concludes that the root cause of intercultural failure is teaching programs that often "highlight and address celebratory rather than critical approaches to diversity, employing 'add-on' or piecemeal approaches" (p. 172). There are a couple of reasons for this according to Lanas. The first reason is that, intercultural understanding does not appear "as relevant to the immediate teaching situation" (p.172). The second reason, however, is related to affective issues such as self and emotion, which are treated as a 'side note' not as imperatives.

Alptekin (2010) points to the role that English plays as a lingua franca in the international arena. In this sense, he considers English as no one's property and devoid of idioms, puns, culture specific pragmatic dimensions, etc. Alptekin views English as a Lingua Franca (ELF) as a "unique case of bilingualism without biculturalism where non-native speakers of English use their own version of the language in a variety of international contexts" (p. 102). In ELF contexts, according to Alptekin (2010), ELF users do not necessarily have the primary knowledge of norms that their native interlocutors possess and even they might not want to communicate following such norms. This inconformity in norms, Alptekin believes, may give rise to misunderstandings given the host of social contexts and the variety of acts that natives and non-natives are involved in.

Lanas's focus is largely on teacher education programs but Celeste Kinginger's (2011) review of Gillian Schaur's book "Interlanguage pragmatic development: The study abroad context" reflects the particularly important role that study abroad programs can play in developing learners' sociolinguistic repertoire. Study abroad programs, according to the author, results in drastic increase in learners' ability to detect and understand the severity of pragmatic infelicities. In the context of ESP too Benson (1994) refers to the structures, values, norms and procedures of cultures that might not match each other and therefore sees it inevitable that the nonparallel structures be taught to learners to be able to assimilate into their target communities. As an example of these nonparallel structures, Cameron (2001) refers to Japanese speakers' frequent use of the word sorry instead of thank you in English which might be misinterpreted by their English interlocutors. The idea of teaching pragmatic meanings also resonates well with Dudley-Evans and St-John (1998) who see teaching cultural values and attitudes as one of the Key issues in all areas of English for Specific Purposes.

The job of pragmatics is to study how speaker-intended meanings are recovered by listeners at the two levels of utterance and force (Thomas, 1995, as cited in Taguchi, 2008). Along the same lines, Spencer-Oatey and Žegarac (2010) put it that the main import of an utterance might not match with the thought expressed by the utterance. The authors quote Thomas (1983) as saying that mismatches in people's pragmalinguistic conventions (linguistic choices available) may result in sociopragmatic (contextual appropriateness of the choices) failure. This is especially the case in second language acquisition as Kasper and BlumKulka (1993) claim. According to these authors, 
pragmalinguistic is one area in which second language learners' weakness is obvious.

Gumperz (1999) believes that to be able to follow the thematic progression of an argument, speakers must be able to recognize the lines of reasoning which are culturally possible. Other forms of communication too in many cases are cultural products and to realize them people need to be familiar with 'contextualization cues' which in Gumperz' terms are the aspects of the surface structure of the message such as co-occurrence of words and prosodic cues. The example that Gumperz provides for misunderstandings arising from inability to recognize prosadic cues is related to a west Indian driver-conductor who uses the expression 'exact change, please' with the passengers who give him large bills. But the second time round articulating the word 'please, with a pause before and extra loudness the passengers impression is that he is rude and threatening. However, Gumperz challenges the idea that the driver did indeed intend to be rude and explains how the passengers' interpretation might have been a case of cross-cultural misunderstanding.

In relation to cross-cultural misunderstanding, Be'al (1992, as cited in Paltridge, 2012), likewise, refers to the way French speakers in a workplace misunderstood English speakers by providing detailed explanation of what had happened to them in response to such questions as 'How are you?' or 'Did you have a good weekend?'. Spencer-Oatey and Žegarac (2010) provide further example by the way Chinese speakers treat the expression 'Where are you going?' as a not as a genuine question requesting information.

The degree of politeness and the way people interpret their interlocutors' interpersonal expressions, is also a serious issue. Brown and Levinson (1988) introduce the concepts of positive and negative politeness. According to these authors, positive politeness refers to saying things that make other people feel pleased. However, negative politeness is related to the listeners' sense of inclusion and right to privacy. Brown and Levinson believe that these politeness strategies are universal but the way they are used may differ in different communities, which again implies instructing L2 learners on these strategies. These observations mean that variation is a norm in pragmatics, especially when people from different cultures come into contact.

Cross-cultural misunderstanding does not occur only in situations in which people speak with each other. Sometimes non-natives refrain from speaking where they are naturally expected to do so which may drive natives to conclude that they are socially inept. This was the case in Cui's (2014) study of a Chinese woman, called Mei, who avoided expressing her gratitude to her host Mary at the party because of the informal topics others brought up and a lack of confidence in her own language proficiency. Allen and Herron (2003), similarly, attribute this reluctance for communication to huge cultural differences that some nonnatives feel to exist between their own culture and the culture in which they have just started living or studying, a feeling that creates extreme anxiety for getting mixed with natives and gaining in competence. Another issue raised by Davis (2007) is resistance to L2 pragmatics of some varieties of English. About his student J, Davis states that this student, who was temporarily living in Australia, was resistant to Australian formulaic expressions believing that American English would serve his needs best. According to Davis, This bias is widespread in South Korea.

In the case of study abroad settings, Kinginger (2013) discusses identity conflicts that can affect both the quality of language learning and the choices that students make to appropriate or reject. Kinginger refers to an American study abroad student who finds the social organization and norms for interaction in his new environment in France quite confusing by seeing that students talk during the class and pay little attention to what professors say. He is further disoriented by the observation that the professors do not engage with the students or monitor their understanding. Patron's (2007, as cited in Kinginger, 2013) too describes French students in Australia witnessing unpredictable and "inexplicable academic practices" (p. 340) and perplexed by what is morally good or bad.

Of course, pragmatic competence, like linguistic competence, is responsive to teaching be it explicit, implicit, or incidental. Among the factors that might affect this competence in the positive direction, especially in study abroad programs, Baker-Smemoe, Dewey, Bown, and Young (2014) point to the length of stay, language use, preprogram competency, and social network development. They also refer to personal factors such as intercultural sensitivity. In fact, Baker-Smemoe, et.al. (2014) found that "the development and makeup of social networks as well as cultural sensitivity were the variables that predicted most of the variance between gainers and non-gainers" (pp. 476-477) in a study abroad program they had focused on. An important factor was social network development which, according to the authors, provides more opportunities for language use, engagement in more complex language, and involvement in extended discourses.

English as an International Language (EIL) or English as a Lingua Franca (ELF) has been one of the hotly-debated issues in recent years. The growth of English into an international language and the diffusion of English across the world have caused considerable tensions in the process of English language teaching. Like Alptekin (2010), Widowson (1994) and Seidlhofer (2003) too believe that English is no longer the sole property of its native speakers. This claim is due to the fact that sixty five percent (Graddol, 1996) of the interactions done in English is among non-native speakers, who do not necessarily follow the Anglo-American way of language use. The increase in the number of non-native speakers of English has resulted in a salient fact about English; not only people who speak English are more likely to be non-native speakers of English than native speakers, but they are most likely to speak to other non-native speakers of English than to native speakers. These people are using English as a language of communication. This means that they do not necessarily need to know anything about English 
or American cultures to be able to communicate effectively. Instead, they need to know something about each other's culture because this knowledge can pave the way or facilitate the mutual understanding.

\section{Procedure}

In this study, we elaborated on a number of important Iranian cultural schemas, namely, 'expressing thankfulness', 'making requests', and 'complimenting' and then explored how these cultural schemas could potentially culminate in cross-cultural misunderstanding when communicating in English.

\subsection{Thankfulness}

Consider the following example.

Iranian Lecturer: I don't know how to thank you!

Turkish Colleague: Come on. You are welcome.

Iranian Lecturer:

No, I cannot forget the kindnessyou

Turkish Colleague: did to me.

Iranian Lecturer:

Oh, don't mention it [confused]

You are really kind. I am really thankful.

Turkish Colleague: You are exaggerating!

Iranian Lecturer: No, you are so kind and I really

Turkish Colleague: thank you!

Iranian Lecturer:

Oh, DON'T exaggerate!

I really appreciate it!

Turkish Colleague:

Sinir etti beni! (He drove mecrazy!) [fierce whisper]

The conversation was between an Iranian and a Turkish lecturer working at a university in Turkey. They were having lunch and one of the researchers in this study was in the same table listening to them. In the conversation between an Iranian lecturer and a Turkish lecturer, the Iranian lecturer's thankfulness to the Turkish lecturer's favor appears to have discomforted the Turkish lecturer, leaving her with the feeling that her help to solve the Iranian lecturer's problem has been overestimated and over-exaggerated. While talking to the Turkish lecturer, she stated that the Iranian lecturer stubbornly insisted on thanking her many times for her contribution. The Iranian lecture on the other hand maintained that he did not find anything wrong with his remarks! Here, the Iranian lecturer appears to have responded to his Turkish colleague's kindness in a way that is appropriate to the Iranian cultural schema of 'thankfulness' while the Turkish lecturer didn't expect to hear repetitive thankfulness for what she did.

The point is that in Iranian culture, repetitive thankfulness is common to express your politeness and courtesy in different forms. So the speakers may exchange some sentences like the ones above to show their politeness. It is noteworthy that contribution given or done by an opposite sex (especially female) might double the number of thankfulness expressions.

The point worth mentioning here is that in interaction among people with different cultural backgrounds, speakers often build on the assumption that their cultural conceptualizations are shared by their hearers. To illustrate, here the Iranian lecturer is interacting on the assumption that his Iranian cultural conceptualization is shared by his partner and this assumption leads to misunderstanding. Therefore, according to Sharifian, interlocutors would first need to minimize the assumption of shared cultural conceptualizations. That is, participants in EIL communicative events would need to constantly remind themselves that other interlocutors may not share the schema, category or metaphor that they are drawing on as a frame of reference in their production and comprehension'.

\subsection{Making Requests}

As far as the issue of making requests is concerned, English speakers normally like the request to be made before the reasons are given while Iranian speakers often prefer to give the reasons for their request before they make it. So, it is said that many Asian cultures are more 'inductive' and that Anglo-American cultures are more 'deductive'. The Iranian speakers might also use "facework" before they approach the main topic. By facework it is meant that asking questions about unrelated issues and saying complimentary things about them in order to pave the ground for making the request is justified because most Iranian speakers find it impolite to make the request directly.

Consider the following conversation.

Iranian lecturer: Last night I couldn't sleep well. I am feeling down and so tired now.

American lecturer: Oh, really? That is too bad.

Iranian lecturer: Yeah, I had a toothache. I think I have

to go to a dentist.

American lecturer: Oh, I am sorry to hear that. Is it painful now?

Iranian lecturer: $\quad$ Yes, it is. I am seeing the doctor tomorrow in the morning.

American lecturer: Oh, yeah.

Iranian lecturer: I am ashamed but could you do me a

American lecturer: What is that? What have you done?!

What can I do for you? [looking puzzled]

Iranian lecturer: Well, I don't know how to say.

American lecturer: [looking confused]

Iranian lecturer: Could you cover my classes tomorrow in the morning?

American lecturer: Sure, man. Don't worry.

Here the Iranian lecturer has decided to use facework and some not totally relevant topics to prepare the ground for making his request. He talks about the problem that he had the last night and has literally translated the Persian expression sharmandam ('I am ashamed') into English before making the request. Actually he has used this expression to express his gratitude to the American lecturer. However, it has made the American lecturer confused because such expression in English might be uttered in a case where somebody has done something wrong and feels 
regretful for doing that. In Iranian English, the concept of 'shame' highlights the fact that the speaker is (painfully) aware of the time and energy that the addressee will invest in order to fulfill his request and that he feels uncomfortable about it.

\subsection{Complimenting}

Complimenting is mainly driven by considerations of 'face' and politeness but to an extent that many foreigners find it an exclusively Iranian phenomenon (Beeman, 1986). Acts and gestures of complimenting or târof, as Iranians call it, include hesitation about making requests and complaints, hesitation about accepting offers and invitations, as well as, offering 'ostensible' invitations (Eslami Rasekh, 2005).

Consider the following example. This interaction was in a Turkish instructor's office.

I'd like to have a cup of coffee. Would

Turkish instructor: you like some? I have tea and coffee in my office.

Iranian friend: $\quad$ No, thank you.

Turkish instructor: Are you sure?

Iranian friend: Yeah, thanks! [with hesitation]

Turkish instructor: $\mathrm{Ok}$

The hesitation about accepting the offer made by the Turkish instructor is deeply rooted in cultural conceptualization of Iranian people and is a characteristic feature of it. Complimenting may be captured by the words 'pleasantries' and 'etiquette'. In order to show politeness, the Iranian friend attempted to behave in a way that is appropriate to Iranian culture. Even though he really would like to have a cup of coffee, he didn't accept the invitation. He expected to be offered many times before expecting the offer. However, the Turkish instructor avoided repeating the offer many times which consequently led to a breakdown in communication between them.

In Iran, the majority of people tend to make ostensible offers and, for instance, can ask people to stay for a meal with them while in many cases they actually do not mean it. They are just making offers to show politeness. Coming from the same cultural backgrounds, Iranian people often realize that the offer is just ostensible. Sometimes it is even difficult for Iranians to identify whether the offer is ostensible or genuine. Foreigners who want to communicate with Iranians in Iran often find the sociocultural basis of this culture the most difficult aspect of it.

\section{Conclusion}

In international contexts two interlocutors may not share the same system of cultural conceptualizations even though they both use English to engage in communication with each other. Speakers are expected to keep in mind that English is now used globally to express various systems of cultural conceptualizations and 'native' speaker competence may not necessarily enable individuals to be effective speakers, particularly if their competence has been exclusively developed in monocultural contexts. Therefore, the notion of 'being proficient' in EIL appears to require more than just the mastery of grammar and lexicon. In the light of the ideas presented above, we may need to consider the notion of EIL proficiency, at least partly, in terms of exploring various systems of cultural conceptualizations and practice in adopting effective communicative strategies when communicating with people from different cultural backgrounds. That is, 'more proficient' speakers are those who have been exposed to, and show familiarity with, various systems of cultural conceptualizations, participating with flexibility in EIL contexts and effectively articulating their cultural conceptualizations. The kind of competence that underpins the skills that are described here may be best termed meta-cultural competence.

In answer to the question of which variety to choose as the EIL teaching model, no matter what variety the teacher speaks, the pedagogical implication is that students need to be exposed to several varieties, to get the real sense of EIL speech situations, in which people who communicate with each other speak different varieties of English. Exposure to different varieties of English can prepare the ground for understanding different Englishes spoken in different parts of the world (Matsuda, 2003, Sharifian, 2009). In a world where the non-native speakers of English outnumber nativespeakers, the percentage of interaction among non-native speakers of English is higher than that among native speakers of English. That is why in the EIL-era having exposure to and being familiar with different varieties of English spoken by both native and non-native speakers of English is accorded a great deal of importance to it.

Sharifian (2010) maintains that World Englishes should be differentiated and explored in terms of not just their phonological and syntactic dimensions, but also in terms of cultural conceptualizations that underlie their semantic and pragmatic levels. Overwhelmingly focusing on the users and uses of English in the native speaker countries and excluding speakers and uses of English in other countries is less likely to prepare students to use English adequately in future communicative events (Matsuda, 2003; Sharifian; 2009). Exposure to different varieties of English through the representation of English as it is used in those countries would help students understand that English use is not limited to the native speaker countries (Matsuda, 2003).

Therefore, EIL does not suggest or support a particular variety of English rather it rejects the idea of any particular variety (Sharifian, 2009). Instead of trying to explore how EIL could be turned into a 'nuclear' language or trying to turn the whole world into a 'homogenous speech community', it might be more helpful to offer a revised model of communication that makes mutual understanding more feasible. Some scholars have tried to suggest phonological and syntactic features for EIL. However, Sharifian (2010) believes that if more than 80 percent of communication in English is now taking place between nonnative speakers, instead of exploring phonological and syntactic dimensions of different varieties of English spoken globally, it is high time to investigate the cultural schemata 
that these speakers draw on while negotiating their cultural meanings. As the results of the study indicate, the Iranian people like many other non-native speakers of English are likely to rely on the first language systems of the Iranian cultural conceptualizations when they interact in English with speakers from different cultural backgrounds. Unfamiliarity with the systems of conceptualizations on which the international speakers of English are relying may lead to various forms and degrees of discomfort and even miscommunication. In the abovementioned examples, we can observe the failure in communication between the Iranian and other users of English, despite the fact that speakers were fluent in English. To put it in a nutshell, instead of relying on the cultural schemata of the native speakers of English to negotiate meaning or to communicate with other users of English, we can seen English in terms of a language which can be used to communicate various systems of cultural conceptualizations.

\section{References}

[1] Allen, H. W., \& Herron, C. (2003). A mixed-methodology investigation of the linguistic and affective outcomes of summer study abroad. Foreign Language Annals, 36, pp.370385 .

[2] Alptekin, C. (2010). Redefining multicompetence for bilingualism and ELF. International Journal of Applied Linguistics, 20(1), pp. 95-110.

[3] Baker-Smemoe, W., Dewey, D. P., Bown, J., \& Martinsen, R. A. (2014). Variables affecting L2 gains during study abroad. Foreign Language Annals, 47(3), pp. 464-486.

[4] Bardovi-Harlig, K. (2013). Awareness of meaning of conventional expressions in second-language pragmatics. Language Awareness, 23(1-2), 41-56.

[5] Beeman, W. O. (1986). Language, Status, and Power in Iran. Bloomington: Indiana University Press.

[6] Benson, M. (1994). Lecture comprehension in an ethnographic perspective. In J. Flowerdew (Ed.), Academic Listening: Research perspectives (pp. 181-198). Cambridge: Cambridge University Press.

[7] Brown, P., \& Levinson, S. L. (1988). Politeness: Some universals in language usage. Cambridge: Cambridge University Press.

[8] Cameron, D. (2001). Working with spoken discourse. London: Sage.

[9] Cui, X. (2014). Getting to the source: An instrument for examining the dynamics of problematic interactions. RELC Journal, 45(2), 197- 210.

[10] Davis, J. M. (2007). Resistance to L2 pragmatics in the Australian ESL context. Language Learning, 57(4), pp. 611649.

[11] Dudley-Evans, T., \& St-John, M. J. (1998). Developments in English for specific purposes: A multidisciplinary approach. Cambridge: Cambridge University Press.
[12] Eslami Rasekh, Z. (2005). Invitations in Persian and English: ostensible or genuine? Intercultural Pragmatics Journal, 2(4), $453-480$.

[13] Graddol, D. (1996). The Future of English? London: British Council.

[14] Gumperz, J. J. (1999). Sociocultural knowledge in conversational inference. In A. Jaworski, \& N. Coupland (Eds.), The discourse reader (pp. 191-211).

[15] Johnstone, B. (2008). Discourse analysis (2nd ed.). Malden, MA: Blackwell Publishing.

[16] Kasper, G., \& Blum-Kulka, S. (1993). Interlanguage pragmatics: An introduction. In G. Kasper \& S. Blum-Kulka (Eds.), Interlanguage pragmatics (pp. 1-17). Oxford: Oxford University Press.

[17] Kinginger, C. (2011). G. Schauer: Interlanguage pragmatic development: The study abroad context. Continuum, 2009. Applied Linguistics, 32(5), pp.572-584.

[18] Kinginger, C. (2013). Identity and language learning in study abroad. Foreign language Annals, 46(3), pp.339-358.

[19] Lanas, M. (2014). Failing intercultural education? 'Thoughtfulness' in intercultural education for student teachers. European Journal of Teacher Education,37(2), pp.171-182.

[20] Littlemore, J., Trautman Chen, P., Koester, A., \& Barnden, J. (2011). Difficulties in metaphor comprehension faced by international students whose first language is not English. Applied Linguistics, 32(4), pp.408- 429.

[21] Littlemore, J. 2001. Metaphor as a source of misunderstanding for overseas students in academic lectures. Teaching in Higher Education, (6)3, pp.333-351.

[22] Matsuda, A. (2003). Incorporating world Englishes in teaching English as an international language. TESOL Quarterly, 37(4), 719-29.

[23] McKay, S. L. (2003). The cultural basis of teaching English as an international language, TESOL Matters, 13(4), 1-2. Retrieved from http://www.tesol.org/s tesol/sec document.asp?CID=192\&DI $\mathrm{D}=1000$.

[24] Paltridge, B. (2012). Discourse analysis (2nd ed.). London: Bloomsbury Publishing PLC.

[25] Schmitt, N. (2014). Size and depth of vocabulary knowledge: What the research shows. Language Learning.64(4), pp. 913951.

[26] Seidlhofer, B. (2003). A concept of international English and related issues: From 'real English' to 'realistic English'. Strasbourg: Council of Europe. Retrieved from http://www.coe.int/t/dg4/linguistic/source/ seidlhoferen.pdf

[27] Sharifian, F. (2009). English as an International Language: An Overview. In F. Sharifian (eds), English as an International Language Perspectives and Pedagogical Issues. Multilingual Matters, (pp. 1 - 18).

[28] Sharifian, F. (2010). Glocalization of English in World Englishes: An Emerging Variety among Persian Speakers of Englis. In M. Saxena and T. Omoniyi (eds). Contending with Globalization in World Englishes. Multilingual Matters. (pp.137-158). 
[29] Spencer-Oatey, H., \& Žegarac, V. (2010). Pragmatics. In N. Schmitt (Ed.), An introduction to applied linguistics (2nd ed.) (pp. 70-88). London: Hoder \& Stoughton Ltd.

[30] Taguchi, N. (2008). Cognition, language contact, and the development of pragmatic comprehension in a study-abroad context. Language Learning, 58(1), 33-71.

[31] Wardhaugh, R., \& Fuller J. M. (2015). An introduction to sociolinguistics (7th ed.). London: Wiley-Blackwell.

[32] Watson, J. R, Siska, P., \& Wolfel, R. L (2013). Assessing gains in language proficiency, Cross-cultural competence, and regional awareness during study abroad: A preliminary study. Foreign Language Annals, 46(1), pp.62-79.

[33] Widdowson, H. G. (1994). The ownership of English. TESOL Quarterly 28(2), pp. 377-88.

[34] Zareva, A. (2010). Multicompetence and L2 users' associative links: Being unlike native like. International Journal of Applied Linguistics, 20(1), 2-22.

[35] Zheng. Y. (2014). The fluctuating development of crosslinguistic semantic awareness: A longitudinal multiple-case study. Language Awareness, 23(4), 369-388. 